\title{
Galactose Ingestion Increases Vascular Permeability and Collagen Solubility in Normal Male Rats
}

\author{
Katherine Chang," Martha Tomlinson," Jay R. Jeffrey," Ronald G. Tilton," William R. Sherman, ${ }^{\star}$ Karen E. Ackermann, ${ }^{\star}$ \\ Richard A. Berger, ${ }^{\ddagger}$ Theodore J. Cicero, ${ }^{\ddagger}$ Charles Kilo, ${ }^{5}$ and Joseph R. Williamson* \\ Departments of ${ }^{*}$ Pathology, ${ }^{\ddagger}$ Psychiatry, and ${ }^{\S}$ Internal Medicine, Washington University School of Medicine, St. Louis, Missouri 63110
}

\begin{abstract}
In view of the similarity of cataracts and neuropathy in galactosefed and diabetic rats, the present experiments were undertaken to determine whether consumption of galactose-enriched diets (10, 25 , or $50 \%$ by weight) also increases collagen crosslinking and permeation of vessels by ${ }^{125} \mathrm{I}$-albumin analagous to that observed in diabetic rats. The observations in these experiments: (a) demonstrate that consumption of galactose-enriched diets for 3 wk selectively increases ${ }^{125} \mathrm{I}$-albumin permeation of the same vascular beds affected in diabetic rats and by diabetic vascular disease in humans (i.e., the aorta and vessels in the eye, kidney, sciatic nerve, and new tissue formed in the diabetic milieu); (b) demonstrate that the susceptibility of the vasculature to aldose reductase-linked injury (increased permeability) varies greatly in different tissues; $(c)$ indicate that collagen solubility (crosslinking) changes in galactose-fed rats differ sharply from those in diabetic rats; and $(d)$ provide new evidence that consumption of galactose-enriched diets induces a hypogonadal state in male rats.
\end{abstract}

\section{Introduction}

The development of cataracts and impaired motor nerve conduction velocity in animals fed galactose-enriched diets is well known (1-4). The similarity of these phenomena to those occurring in diabetic animals and their association, in both conditions, with the accumulation of polyols (galactitol and sorbitol in galactose-fed and diabetic animals respectively) has been interpreted as evidence supporting the hypothesis that increased metabolism of glucose by the polyol pathway is an important factor in the pathogenesis of diabetic cataracts and neuropathy (5-7). Additional support for this hypothesis has been provided by evidence that five structurally different chemical inhibitors of aldose reductase, the enzyme that catalyzes formation of galactitol and sorbitol from galactose and glucose respectively, prevent and reverse cataracts and neuropathy induced by diabetes and galactose ingestion (5-15).

The possibility that the polyol pathway might also play a role in diabetic vascular disease is suggested by reports demonstrating aldose reductase activity in vessels (retina [16-18], aorta [14-20], and glomeruli [21, 22]) as well as evidence that

Address correspondence and reprint requests to Dr. Williamson, Washington University School of Medicine, Department of Pathology, $660 \mathrm{~S}$. Euclid Avenue, St. Louis, MO 63110.

Received for publication 16 December 1985 and in revised form 30 June 1986.

J. Clin. Invest.

(c) The American Society for Clinical Investigation, Inc.

0021-9738/87/02/0367/07 \$1.00

Volume 79, February 1987, 367-373 galactose ingestion causes thickening of retinal capillary basement membranes (which is prevented by inhibitors of aldose reductase) in rats (23-25) and retinal capillary microaneurysms in dogs (26). We have recently reported that diabetes-induced increased vascular permeability and polyol levels in new tissue formed in diabetic rats (27) are prevented by castration (27) and by an inhibitor of aldose reductase $(29,30)$. Diabetes-induced increases in collagen crosslinking, which appear to be mediated by lysyl oxidase (31), were prevented by castration (which did not affect plasma glucose levels) but were unaffected by the aldose reductase inhibitor.

The studies described in this paper were undertaken to: $(a)$ investigate whether imbalances in polyol metabolism associated with galactose ingestion also increase vascular permeation by ${ }^{125} \mathrm{I}$-albumin and collagen crosslinking in new granulation tissue, comparable to that induced by diabetes; and $(b)$ to assess effects of galactose ingestion on ${ }^{125} \mathrm{I}$-albumin permeation in other tissues involved by diabetic vascular disease in humans.

\section{Methods}

Animals. Male Sprague-Dawley rats weighing $180-280 \mathrm{~g}$ were divided into four groups. Group I (controls) was fed ground rat chow mixed with equal parts by weight of dextrin; group II was fed ground chow containing $10 \%$ (by weight) galactose; group III was fed $25 \%$ galactose; and group IV $50 \%$ galactose mixed with ground chow. The day before initiation of the diet, sterile preweighed polyester fabric was implanted subcutaneously over the dorsolateral aspect of the thigh, as described in previous publications $(27,31)$, to induce angiogenesis and new granulation tissue formation. $3 \mathrm{wk}$ later, ${ }^{125} \mathrm{I}$-albumin permeation, collagen crosslinking, and levels of polyols and myo-inositol were assessed in the new granulation tissue. Albumin permeation also was assessed in several other tissues including eyes, aorta, brain, heart, skeletal muscle, kidney, skin, cecum, and sciatic nerve.

The effects of two structurally different aldose reductase inhibitors $(11,12)$ (sorbinil and tolrestat, generously provided by Pfizer, Inc., New York, NY, and Ayerst Laboratories, New York, NY, respectively) on galactose-induced albumin permeation were assessed by adding sufficient quantities of each inhibitor to ground rat chow to provide a daily intake of $\sim 0.1 \mathrm{mmol}$ inhibitor $/ \mathrm{kg}$ body weight per $\mathrm{d}$.

Assessment of vascular permeability. The techniques for preparation of radiolabeled tracers and for assessment of ${ }^{125}$ I-albumin permeation of vessels and crosslinking of collagen have been published $(31,32)$ and will be described only briefly. Assessment of vascular permeation by albumin is based on quantification of ${ }^{125} \mathrm{I}$-albumin, ${ }^{51} \mathrm{Cr}$-red blood cell $(\mathrm{RBC})^{1}$, and ${ }^{57} \mathrm{Co}$-EDTA in blood and tissues sampled 6.5-8 min after intravenous injection of the tracers (32) in rats anesthetized with intraperitoneal Nembutal $(35 \mathrm{mg} / \mathrm{kg})$ or Inactin $(\sim 60 \mathrm{mg} / \mathrm{kg})$. Because galactose-fed rats (and diabetic rats) tend to be more sensitive to anesthetic agents, as reflected in lower blood pressures, the dose of anesthetic was

1. Abbreviations used in this paper: GC/MS, gas chromatography-mass spectrometry; RBC, red blood cell; TBIR, tissue-to-blood isotope ratio; TMS, trimethylsilyl. 
reduced by $\sim 25 \%$ in galactose-fed rats. The index of albumin permeation used in these studies, the tissue-to-blood-isotope ratio (TBIR-I/Cr) is derived from the formula: TBIR-I/Cr $=\left({ }^{125} \mathrm{I}-\mathrm{BSA} /{ }^{51} \mathrm{Cr}-\mathrm{RBC}\right)$ for tissue/ $\left({ }^{125} \mathrm{I}-\mathrm{BSA} /{ }^{51} \mathrm{Cr}-\mathrm{RBC}\right)$ for blood, where BSA is bovine serum albumin. A TBIR-I/Cr $>1$ indicates that the volume of distribution of albumin relative to that of red cells is greater in the tissue than in large vessels and is indicative of permeation of the vasculature by albumin into the extravascular space. Because the capillary hematocrit is somewhat lower than that of large vessels (discussed in reference 32), the TBIR-I/Cr is always slightly $>1$.

While the terms increased vascular permeability and increased vascular permeation by albumin are sometimes used interchangeably, it should be understood that these two terms are not synonymous. Permeability refers to the porosity (i.e., pore size, number, and surface area) of the vessel wall, whereas permeation refers to the movement of a tracer molecule, i.e., ${ }^{125}$ I-albumin, across the vessel wall. While an increase in the number and/or size of vascular pores large enough to accommodate albumin will be manifested by an increase in albumin permeation, an increase in albumin permeation also may occur as a consequence of hemodynamic changes leading to an increase in pressure gradients across vessel walls. Such changes would increase the filtration (permeation) of plasma water and proteins (including albumin) through existing pores without any change in porosity of the vessel wall. At the present time we do not know the mechanism(s) responsible for the diabetes-induced increase in albumin permeation of vessels in this model.

The TBIR for the ${ }^{57} \mathrm{Co}-\mathrm{EDTA} /{ }^{51} \mathrm{Cr}-\mathrm{RBC}$ (TBIR-Co/Cr) also was determined. Because ${ }^{57} \mathrm{Co}$-EDTA is a much smaller molecule than ${ }^{125} \mathrm{I}$ albumin, it permeates vessel walls much more readily and accesses virtually the entire extracellular space. If only the TBIR-I/Cr is determined and it is low or close to 1 , it is not possible to know whether the low value is because of the permeability characteristics of the vessel or because the interstitial fluid space is so small that it is limiting, or because blood flow was so low that little albumin was available to access the interstitial fluid space. On the other hand, a low TBIR-I/Cr in the face of a high TBIR-Co/Cr indicates that the permeability characteristics of the vessel wall limited permeation of the vessel by ${ }^{125} \mathrm{I}$-albumin.

Assessment of collagen crosslinking and nonenzymatic glycosylation of granulation tissue. Because solubility of collagen in neutral salt solutions and dilute acids is inversely related to the extent of intermolecular crosslinks (33), we have quantified collagen solubility in $0.5 \mathrm{M}$ acetic acid as an index of collagen crosslinking (31). The implant tissue is first finely minced with scissors and a razor blade, and extracted with $0.15 \mathrm{M} \mathrm{NaCl}$ in $50 \mathrm{mM}$ Tris (at neutral $\mathrm{pH}$ ) at $4^{\circ} \mathrm{C}$ for $4-6 \mathrm{~h}$ to wash out plasma proteins and other soluble noncollagenous proteins. The minced tissue is then centrifuged and the residue is extracted at $4^{\circ} \mathrm{C}$ in $0.5 \mathrm{M}$ acetic acid ( $1 \mathrm{ml} / 100 \mathrm{mg}$ wet weight of implant) for $48 \mathrm{~h}$ with constant shaking. After centrifugation at $37,000 \mathrm{~g}$ for $60 \mathrm{~min}$, the supernatant and pellet are lyophylized and then hydrolyzed in $0.3 \mathrm{~N}$ oxalic acid for $2 \mathrm{~h}$ at $100^{\circ} \mathrm{C}$. The samples are then cooled to room temperature and proteins are precipitated by addition of TCA. Hexoses bound nonenzymatically to proteins in the supernatants are measured as 5-hydroxymethylfurural by the thiobarbituric acid method (34). The TCA precipitates are lyophylized and hydrolyzed in $6 \mathrm{~N} \mathrm{HCl}$ for $24 \mathrm{~h}$ at $100^{\circ} \mathrm{C}$ for determination of hydroxyproline (35) and total protein (36). Soluble and insoluble collagen are estimated from the hydroxyproline content of the supernatant and pellet, respectively, using a correction factor of 10 (based on evidence that hydroxyproline accounts for $\sim 10 \%$ of the weight of type I collagen) (37). Total collagen is considered equal to the sum of the soluble and insoluble fractions.

Measurement of tissue levels of polyols and myo-inositol. Chemical ionization gas chromatography-mass spectrometry (GC/MS) using ammonia as reagent gas and helium as carrier was used to measure tissue levels of the trimethylsilyl (TMS) derivatives of these substances (38). Because TMS sorbitol does not separate from TMS galactitol or TMS mannitol, if either of these latter polyols are present they will be included in the values reported as sorbitol. In control rats, tissue levels of polyols are presumed to consist primarily of sorbitol, whereas in galactose-fed rats they would reflect primarily galactitol.
The method of analysis was to extract weighed tissue samples $(\sim 50$ $\mathrm{mg}$ wet weight) with water $(500 \mu \mathrm{l})$ and $100 \mu \mathrm{l}$ of $2-\left[{ }^{2} \mathrm{H}\right]-2-{ }^{18} \mathrm{O}-m y o-$ inositol $(46 \mathrm{ng} / \mu \mathrm{l})$ as internal standard, in $1.5 \mathrm{ml}$ of polypropylene centrifuge tubes, at $100^{\circ} \mathrm{C}$ for $15 \mathrm{~min}$ in a heated aluminum block. The samples are then cooled, and $25 \mu$ leach of $0.3 \mathrm{~N} \mathrm{ZnSO}_{4}$ and $0.3 \mathrm{~N}$ $\mathrm{Ba}(\mathrm{OH})_{2}$ are added to complete the precipitation of protein. The tubes are then centrifuged and aliquots (as large as possible) are lyophylized in 0.5-dram vials with Teflon-lined screw caps. The dried samples are treated with $200 \mu \mathrm{l}$ of $1: 1(\mathrm{vol} / \mathrm{vol})$ of dry pyridine and N,O-bis-(trimethylsilyl)-trifluoroacetamide containing $10 \%$ trimethylsilyl chloride (Regis Chemical Co., Morton Grove, IL). After $24 \mathrm{~h}$ at room temperature, samples are analyzed (or stored at $-70^{\circ} \mathrm{C}$ in a jar containing Drierite until analysis). GC/MS is carried out on a model 3300 chemical ionization instrument (Finnigan Corp., Sunnyvale, CA) under the following conditions: $\mathrm{NH}_{3}$ reagent gas 0.5 torr, He carrier gas about $20 \mathrm{cc} / \mathrm{min}, 5 \mathrm{ft}$ $\times 1 / 4$-in optical density glass column packed with $3 \%$ SE-30 on Gas Chrom $\mathrm{Q}, 210^{\circ} \mathrm{C}$ isothermal. Under these conditions sorbitol elutes at $\sim 3 \mathrm{~min}$ and myo-inositol at $5 \mathrm{~min}$. Dilutions of a mixture of these substrates of appropriate range are measured each day of analysis and used for quantitation. The protonated molecular ions used in each analysis are: $\mathrm{m} / \mathrm{z}$ 615 , TMS sorbitol; $\mathrm{m} / \mathrm{z} 613$, TMS myo-inositol; and $\mathrm{m} / \mathrm{z} 616,\left[{ }^{2} \mathrm{H}\right]-{ }^{18} \mathrm{O}$ myo-inositol.

Other analyses. Plasma glucose levels and galactose levels were determined by the glucose oxidase and galactose oxidase methods $(39,40)$. Testosterone was extracted from plasma using benzene/petroleum ether (2:5) and was assayed by radioimmunoassay as described elsewhere (41) using a highly specific testosterone antiserum supplied by P. N. Rao (Southwest Foundation for Research and Education, San Antonio, TX). Differences between groups were assessed by $t$ test on arithmetic means and standard deviations unless otherwise indicated.

\section{Results}

Consumption of 10,25 , and $50 \%$ galactose-enriched diets for 3 wk caused corresponding marked incremental increases in ${ }^{125} \mathrm{I}$ albumin permeation of the vasculature in the eye and in new granulation tissue vessels (Table I) and a somewhat smaller, but statistically significant increase in ${ }^{125} \mathrm{I}$-albumin permeation in the aorta. ${ }^{125} \mathrm{I}$-albumin permeation also was markedly increased in the kidney and in sciatic nerve of (Inactin-anesthetized) rats fed $50 \%$ galactose diets (Table I).

Data from an independent experiment performed to assess effects of aldose reductase inhibitors on ${ }^{125} \mathrm{I}$-albumin permeation in rats fed a $50 \%$ galactose diet are shown in Table II. In this experiment, it can be seen that galactose-induced increases in ${ }^{125} \mathrm{I}$-albumin permeation in granulation tissue and aorta were much larger, whereas that in the eye was smaller, than in the previous experiment. The only other tissue in which ${ }^{125} \mathrm{I}$-albumin permeation was increased (relative to controls) was the cecum. Both aldose reductase inhibitors virtually normalized ${ }^{125} \mathrm{I}$-albumin permeation in granulation tissue, aorta, and the eye, but had no effect on the cecum or on tissues in which ${ }^{125} \mathrm{I}$-albumin permeation was unaffected by galactose ingestion. Effects of aldose reductase inhibitors on albumin permeation in forelimb muscle and sciatic nerve have not been examined. The effects of aldose reductase inhibitors on albumin permeation in the kidney are not shown because subsequent studies (in diabetic rats) indicate that the tracer equilibration time used in these experiments was too long to permit detection of such effects.

TBIR-Co/Cr values differed greatly in different tissues of control rats, however, they were unaffected by galactose ingestion except for a small increase in brain $(\mathrm{t}=2.42, \mathrm{t}<0.05)$ (Table III).

The solubility of granulation tissue collagen from rats fed $10 \%$ galactose $(\sim 21 \%)$ was virtually identical to that of controls 
Table I. Effect of Galactose Ingestion for 3 wk on Vascular Permeation by ${ }^{125}$ I-albumin in New Granulation Tissue Vessels, and in the Eyes, Aorta, Kidneys, and Sciatic Nerve

\begin{tabular}{|c|c|c|c|c|c|}
\hline Group & Granulation tissue & Eyes & Aorta & Kidney & Sciatic nerve \\
\hline Controls & $\begin{array}{l}1.90 \pm 0.10^{*} \\
(11)\end{array}$ & $\begin{array}{l}2.40 \pm 0.28 \\
(11)\end{array}$ & $\begin{array}{l}2.33 \pm 0.13 \\
(5)\end{array}$ & $\begin{array}{l}4.93 \pm 0.73 \\
(7)\end{array}$ & $\begin{array}{l}2.23 \pm 0.19 \\
(8)\end{array}$ \\
\hline $10 \% \mathrm{Gal}^{\ddagger}$ & $\begin{array}{l}2.20 \pm 0.08^{\S} \\
(5)\end{array}$ & $\begin{array}{l}2.60 \pm 0.21 \\
(5)\end{array}$ & $\begin{array}{l}2.62 \pm 0.28 \\
(6)\end{array}$ & - & - \\
\hline $25 \%$ Gal. & $\begin{array}{l}2.52 \pm 0.13^{\delta} \\
(8)\end{array}$ & $\begin{array}{l}3.59 \pm 0.27^{\S} \\
(8)\end{array}$ & $\begin{array}{l}2.67 \pm 0.38 \\
(7)\end{array}$ & - & - \\
\hline $50 \%$ Gal. & $\begin{array}{l}3.25 \pm 0.29^{\S} \\
(12)\end{array}$ & $\begin{array}{l}5.68 \pm 0.31^{\S} \\
\text { (11) }\end{array}$ & $\begin{array}{l}2.85 \pm 0.36^{\prime \prime} \\
(5)\end{array}$ & $\begin{array}{l}8.71 \pm 0.69^{\S} \\
(8)\end{array}$ & $\begin{array}{l}3.49 \pm 0.42^{\S} \\
(8)\end{array}$ \\
\hline
\end{tabular}

${ }^{*}$ Mean \pm SD (with number of animals in parentheses) of the tissue to blood isotope ratio (TBIR) derived from the formula: TBIR $=\left({ }^{125}\right.$ I-BSA/ ${ }^{51} \mathrm{Cr}-\mathrm{RBC}$-tissue $) /\left({ }^{125} \mathrm{I}-\mathrm{BSA} /{ }^{51} \mathrm{Cr}-\mathrm{RBC}-\right.$ blood). ${ }^{\ddagger}$ Galactose (by weight) in diet. ${ }^{\S}$ Significantly different from controls at $P<0.001$. " Significantly different from controls at $P<0.025$.

$(\sim 24 \%)$ as Table IV shows. In contrast, collagen solubility increased significantly to $\sim 29 \%$ ( $P<0.025$ vs. controls) in rats fed $25 \%$ galactose and to $36 \%(P<0.001)$ in those fed $50 \%$ galactose. Total collagen accumulation was the same in all groups of rats. Hexoses bound to granulation tissue protein by ketoamine linkage were increased by $10 \%$ in rats fed 25 and $50 \%$ galactose $(\mathrm{t}=3.41, P<0.005$, and $\mathrm{t}=2.71, P<0.025$, respectively).

Plasma glucose levels at the time of sacrifice (Table V) were increased $18 \%$ in rats fed $25 \%$ galactose $(\mathrm{t}=2.32, P<0.05)$ but did not differ from controls in rats fed 10 and $50 \%$ galactose diets. Plasma galactose levels were increased $\sim 2.5$ times in rats fed $10 \%$ galactose $(\mathrm{t}=3.03, P<0.01), \sim 11.5$ times in those fed $25 \%$, and $\sim 8$ times in those fed $50 \%$ galactose diets $(t$ $=24.35, P<0.001$, and $\mathrm{t}=6.94, P<0.001$, respectively). Body weight gains were not significantly affected in rats fed 10 and $25 \%$ diets (Table V), however, rats fed $50 \%$ galactose gained significantly less weight than controls $(\mathrm{t}=2.64, P<0.025)$ and rats fed $25 \%$ galactose $(\mathrm{t}=2.99, P<0.01)$. Prostate weights, expressed as a percentage of final body weight, were decreased by $17 \%$ in rats fed 25 and $50 \%$ galactose diets $(t=5.26, P<0.001$ vs. controls) (Table V). Plasma testosterone levels in rats fed
$50 \%$ galactose diets were markedly reduced $(\mathrm{t}=3.49, P<0.005)$ (Table V).

Granulation tissue levels of polyols were increased dramatically in rats fed $50 \%$ galactose to levels $\sim 135$ times those observed in controls $(\mathrm{t}=10.95, P<0.001)$ (Table VI). myo-Inositol levels, on the other hand, were virtually identical in galactosefed and control rats. Both inhibitors of aldose reductase markedly reduced, but did not completely normalize, tissue polyol levels (Table VI).

\section{Discussion}

The finding that galactose ingestion resulted in increased ${ }^{125} \mathrm{I}$ albumin permeation of the aorta and of vessels in the eyes, kidney, sciatic nerve, and new granulation tissue, but not in skin, skeletal muscle, brain, testes, and heart indicates that the vasculature in different tissues varies greatly in its susceptibility to polyol-linked injury. The finding that two structurally different inhibitors of aldose reductase largely prevented these galactoseinduced increases in vascular permeability indicates that galactose-induced vascular injury is linked to vascular aldose reductase activity. Further studies are needed to determine whether tissue

Table II. Effects of Aldose Reductase Inhibitors (Sorbinil and Tolrestat Administered at a Dose of $\sim 0.1 \mathrm{mM} / \mathrm{kg} / \mathrm{d}$ ) on ${ }^{125} \mathrm{I-BSA}$ Permeation of Tissues in Rats Fed 50\% Galactose for 3 wk

\begin{tabular}{lllll}
\hline Tissue & Control (7)* & $50 \%$ Galactose (8) & Gal. $+0.1 \mathrm{mM}$ sorbinil (7) & Gal. $+0.1 \mathrm{mM}$ tolrestat (8) \\
\hline Granulation tissue & $1.99 \pm 0.02^{\ddagger}$ & $3.90 \pm 0.30^{\S}$ & $2.16 \pm 0.12$ & $2.19 \pm 0.07$ \\
Aorta & $2.56 \pm 0.12$ & $3.87 \pm 0.22^{\S}$ & $2.82 \pm 0.25$ & $3.06 \pm 0.17$ \\
Eye & $2.43 \pm 0.39$ & $3.11 \pm 0.39^{\| 1}$ & $2.37 \pm 0.19$ & $2.61 \pm 0.20$ \\
Cecum & $2.74 \pm 0.63$ & $3.82 \pm 0.17^{\S}$ & $3.67 \pm 0.46$ & $3.21 \pm 0.73$ \\
Stomach & $2.24 \pm 0.23$ & $2.42 \pm 0.11$ & $2.52 \pm 0.26$ & $2.64 \pm 0.30$ \\
Brain & $1.60 \pm 0.14$ & $1.72 \pm 0.02$ & $1.70 \pm 0.07$ & $1.68 \pm 0.06$ \\
Skin & $2.13 \pm 0.21$ & $2.18 \pm 0.25$ & $2.06 \pm 0.07$ & $2.06 \pm 0.08$ \\
Heart & $1.89 \pm 0.31$ & $2.06 \pm 0.16$ & $2.06 \pm 0.16$ & $2.10 \pm 0.22$ \\
Forelimb muscle & $2.30 \pm 0.33$ & $2.09 \pm 0.34$ & - & - \\
Kidney & $3.98 \pm 0.29$ & $8.27 \pm 0.91^{\S}$ & - & - \\
\hline
\end{tabular}

${ }^{*}$ No: of animals. ${ }^{\ddagger}$ Mean \pm SD of TBIR derived from the formula: TBIR $=\left({ }^{125} \mathrm{I}-\mathrm{BSA} /{ }^{51} \mathrm{Cr}-\mathrm{RBC}\right.$-tissue $) /\left({ }^{125} \mathrm{I}-\mathrm{BSA} /{ }^{51} \mathrm{Cr}-\mathrm{RBC}-\mathrm{blood}\right)$.

${ }^{\S}$ Significantly different from controls at $P<0.001$. "Significantly different from controls at $P<0.005$. 
Table III. Tissue Permeation by ${ }^{57}$ Co-EDTA in Rats

Fed a Diet Containing 50\% Galactose (by weight) for 3 wk

\begin{tabular}{lcc}
\hline Tissue & Control & $\begin{array}{l}50 \% \\
\text { Galactose }\end{array}$ \\
\hline Granulation tissue (7)* & $63.3 \pm 7.9^{\ddagger}$ & $68.3 \pm 7.9$ \\
Aorta (7) & $25.3 \pm 4.0$ & $21.2 \pm 3.2$ \\
Eye (7) & $80.9 \pm 13.3$ & $82.4 \pm 7.0$ \\
Cecum (7) & $71.9 \pm 10.8$ & $72.4 \pm 7.9$ \\
Stomach (7) & $42.5 \pm 3.8$ & $43.7 \pm 5.6$ \\
Brain (7) & $2.5 \pm 0.2$ & $2.9 \pm 0.4$ \\
Skin (7) & $74.3 \pm 8.4$ & $74.1 \pm 7.0$ \\
Forelimb muscle (9) & $49.5 \pm 13.5$ & $43.3 \pm 6.3$ \\
Heart (7) & $7.4 \pm 1.4$ & $8.0 \pm 1.0$ \\
Kidney (8) & $164.0 \pm 53.9$ & $177.3 \pm 59.4$ \\
Sciatic nerve (8) & $32.8 \pm 8.3$ & $32.8 \pm 7.2$ \\
\hline
\end{tabular}

* No. of animals in parentheses.

* Expressed as the mean \pm SD of the TBIR derived from the formula TBIR-Co $/ \mathrm{Cr}-{ }^{57} \mathrm{Co}$-EDTA $/{ }^{51} \mathrm{Cr}-\mathrm{RBC}$ (tissue) $/{ }^{57} \mathrm{Co}-\mathrm{EDTA} /{ }^{51} \mathrm{Cr}-\mathrm{RBC}$ (blood).

differences in susceptibility to polyol-linked vascular injury are related to quantitative or qualitative differences in polyol metabolism and associated metabolic imbalances in endothelial cells or to differences in the ability of endothelial cells in different tissues to maintain functional integrity in the face of increased polyol metabolism. It is of interest, in this regard that isolated canine cerebral microvessels do accumulate polyols when incubated in vitro, although the amount of polyol produced is only $\sim 50 \%$ of that produced by canine retinal vessels (18).

The increased albumin permeation in the aorta, eyes, and kidney in these galactose-fed rats contrasts sharply with the absence of such changes previously reported in diabetic rats (27). More recent studies indicate that this apparent difference in al-

Table IV. Collagen Solubility and Accumulation and Nonenzymatic Glycosylation of New Granulation Tissue Formed During the 3-wk Period After Initiation of Galactose Feeding

\begin{tabular}{llll}
\hline Group & $\begin{array}{l}\text { Collagen } \\
\text { solubility* }\end{array}$ & $\begin{array}{l}\text { Collagen } \\
\text { content }^{*}\end{array}$ & $\begin{array}{l}\text { Nonenzymatic } \\
\text { glycosylation }\end{array}$ \\
\hline Controls (8) & $23.9 \pm 3.7^{\sharp}$ & $73 \pm 3$ & $1.93 \pm 0.15$ \\
$10 \%$ galactose (6) & $21.0 \pm 3.0$ & $74 \pm 3$ & $1.94 \pm 0.06$ \\
$25 \%$ galactose (8) & $29.0 \pm 3.4^{* *}$ & $74 \pm 4$ & $2.13 \pm 0.07^{\ddagger \pm}$ \\
$50 \%$ galactose (6) & $35.8 \pm 3.6^{\$ 8}$ & $76 \pm 5$ & $2.11 \pm 0.07^{\text {III }}$ \\
\hline
\end{tabular}

* Collagen solubility expressed as percentage of total collagen soluble in $0.5 \mathrm{M}$ acetic acid.

${ }^{\ddagger}$ Collagen accumulation expressed as micrograms collagen per milligram implant.

${ }^{8}$ Nonenzymatic glycosylation expressed as nanomoles HMF (5-hydroxymethyl-furfural) per milligram of granulation tissue protein (including collagen plus all other unidentified proteins).

"No. animals in parentheses on diets containing $0,10,25$, or $50 \%$ galactose by weight.

$'$ 'Mean \pm SD.

** Significantly different from controls at $P<0.025$, from $10 \%$ galactose-fed rats at $P<0.001$, and from 50\% galactose-fed rats at $P$

$<0.005$.

¥ Significantly different from controls at $P<0.005$.

$\$$ Significantly different from controls at $P<0.001$.

IIII Significantly different from controls at $P<0.025$. bumin permeation of vessels in galactose-fed vs. diabetic rats is quantitative rather than qualitative and merely reflects differences in the severity of vascular injury. In the previously published studies in diabetic rats, and in the present study in galactose-fed rats, a tracer equilibration time of 6.5-8 min was used. We have since found that: $(a)$ a longer tracer equilibration time (i.e., $30 \mathrm{~min}$ ) is required to detect diabetes-induced increased albumin permeation in the eye (42) and in the aorta (43); and (b) diabetes-induced increased albumin permeation in the kidney is consistently demonstrable in rats anesthetized with Inactin (43), but is highly variable in rats anesthetized with Nembutal. The longer tracer equilibration time required to demonstrate diabetes-induced increased albumin permeation in the eyes and aorta of diabetic rats than is needed to detect corresponding changes in galactose-fed rats suggests that vascular injury is more severe in galactose-fed than in diabetic rats. This interpretation is consistent with evidence that galactose-fed rats develop cataracts in a much shorter time period than diabetic rats (44).

The finding that ${ }^{125} \mathrm{I}$-albumin permeation was increased in the sciatic nerve of galactose-fed rats is consistent with evidence that albumin permeation is increased in the sciatic nerve (Evans' blue technique) of alloxan-diabetic rats (45) and the sural nerve (radioimmunoassay technique) of human diabetics (46). On the other hand, Malmgren et al. (47) reported that the water content was increased but permeation by horseradish peroxidase was not increased in the sciatic nerve of galactose-fed Wistar rats; similarly, Jacobsen et al. (48) reported that the water content was increased although albumin permeation (Evans' blue technique) was not increased in the sciatic nerve of streptozotocindiabetic Wistar rats. The discordance in respect to the demonstration of increased vascular permeability in these different reports may be accounted for by methodological differences in the techniques used to assess vascular permeability as well as by differences in the age and strain of rats used. Mitchell (49) has reported that the Wistar strain of rats is particularly resistent to the development of galactose-induced cataracts and that in more susceptible strains of rats the rate of development and total incidence of cataracts are much higher in young rats than in older ones.

Thus, the vascular beds in which ${ }^{125} \mathrm{I}$-albumin permeation is increased by galactose ingestion do in fact correspond to those affected in diabetic rats and to vessels affected by complications in human diabetics. This finding supports the hypothesis that imbalances in sorbitol/inositol metabolism play an important role in mediating diabetes-induced vascular injury. This interpretation is further supported by evidence that galactose ingestion also causes: $(a)$ retinal capillary basement membrane thickening in rats (indistinguishable from that observed in diabetic rats and humans), which is prevented by inhibitors of aldose reductase (23-25), and (b) retinal capillary microaneurysms in dogs (26). Additional studies are required to determine whether there is any causal relationship between increased permeation of the vasculature by macromolecules (i.e., ${ }^{125}$ I-albumin) and capillary basement membrane thickening or whether these two phenomena are independent manifestations of galactose effects on the vasculature. It is noteworthy, however, that the vascular permeability changes are evident within $3 \mathrm{wk}$ in diabetic (27) and in galactose-fed rats, whereas the capillary basement membrane thickening in galactose-fed rats (23-25) and retinal microaneurysms in dogs (26), required many months to several years, respectively, to develop.

It is unclear why new granulation tissue vessels formed in 
Table V. Effects of Galactose Ingestion (for 3 wk) on Plasma Glucose and Galactose Levels, on Changes in Body Weight and Prostate Weight, and on Plasma Testosterone Levels

\begin{tabular}{|c|c|c|c|c|c|}
\hline Group & Plasma glucose* & Plasma galactose* & Increase in body weight ${ }^{\ddagger}$ & Prostate weight & Plasma testosterone" \\
\hline Controls (11) & $122 \pm 20$ & $7 \pm 4$ & $22.9 \pm 9.8$ & $0.16 \pm 0.02$ & $15.1 \pm 10.1(8)$ \\
\hline $10 \%$ galactose $(6)$ & $128 \pm 30$ & $18 \pm 11$ & $17.3 \pm 3.0$ & $0.17 \pm 0.01$ & - \\
\hline $25 \%$ galactose $(8)$ & $144 \pm 21^{* *}$ & $81 \pm 9^{\ddagger \pm}$ & $21.9 \pm 5.5$ & $0.14 \pm 0.01^{\$ \S}$ & - \\
\hline $50 \%$ galactose (13) & $116 \pm 22$ & $58 \pm 24^{\ddagger \ddagger}$ & $14.5 \pm 5.5$ & $0.13 \pm 0.02^{111 \mathrm{I}}$ & $4.1 \pm 1.4(6)^{11}$ \\
\hline
\end{tabular}

* Expressed as mean \pm SD in milligrams per decaliter. ${ }^{\ddagger}$ Difference in initial and final body weights expressed as a percentage of initial weight. ${ }^{\S}$ Expressed as a percentage of final body weight. "Expressed as nanograms per milliliter. ' No. animals in parentheses. ${ }^{* *}$ Significantly different from controls at $P<0.05$. "\$ Significantly different from controls at $P<0.001$. Significantly different from controls at $\pm P<0.025$. IIII Significantly different from rats fed $10 \%$ galactose at $P<0.005$. "Significantly different from controls at $P<0.005$ ( $t$ test performed on natural logarithm-transformed data).

the diabetic or galactosemic milieu should be more readily permeated by ${ }^{125} \mathrm{I}$-albumin than neighboring connective tissue vessels (from which the new vessels must be derived) present in overlying skin and/or muscle before the onset of diabetes (27) or galactose ingestion. Nevertheless, this finding is consistent with well documented observations that new vessels formed by neovascularization of the retina in human diabetics are permeated by fluorescein to a much greater extent than neighboring retinal vessels whose origin antedates the onset of diabetes $(50$, 51). While these observations (in rats and humans) could be accounted for by differences in maturation of these new $v$ s. the older vessels, this would seem to be an unlikely explanation since the magnitude of the differences is not diminished after 6 mo of galactose ingestion or diabetes of comparable duration (unpublished observations). Alternatively, angiogenesis in the galactosemic or diabetic milieu may result in formation of vessels whose intrinsic functional integrity is compromised or in vessels that are more susceptible to injury linked to increased flux of hexoses via the polyol pathway.

The finding that granulation tissue polyol (presumably galactitol) levels were increased $\sim 135$ fold in these galactose-fed rats whereas the polyol (presumably sorbitol) content of granulation tissue of diabetic rats is increased by only about two-

Table VI. Effects of Galactose Ingestion (for $3 w k$ ) and Inhibitors of Aldose Reductase on Granulation Tissue Polyol and myo-Inositol Content

\begin{tabular}{lcc}
\hline & Polyols* & myo-Inositol \\
\hline Controls $(11)^{\S}$ & $30 \pm 16^{\|}$ & $939 \pm 204$ \\
$50 \%$ galactose (7) & $4069 \pm 510^{*}$ & $842 \pm 76$ \\
$\begin{array}{l}50 \% \text { galactose }+0.1 \mathrm{mM} \\
\quad \text { sorbinil (7) }\end{array}$ & $309 \pm 52^{* *}$ & $810 \pm 64$ \\
$\begin{array}{l}50 \% \text { galactose }+0.1 \mathrm{mM} \\
\quad \text { tolrestat (7) }\end{array}$ & $248 \pm 40^{* *}$ & $773 \pm 62$ \\
\hline
\end{tabular}

* Tissue levels of polyols expressed as nanomoles per gram wet weight. Polyols are probably comprised primarily of sorbitol in controls and galactitol in the groups fed the $50 \%$ galactose diet.

${ }^{\ddagger}$ myo-Inositol expressed as nanomoles per gram wet weight of tissue.

${ }^{\S}$ No. of animals in parentheses.

"Mean \pm SD.

'Significantly different from controls at $P<0.001$.

** Significantly different from controls and from rats fed $50 \%$ galactose at $P<0.001$. fold $(28,29)$ is consistent with evidence that the $K_{\mathrm{m}}$ of aldose reductase for D-glucose is three times that of D-galactose (52) and that galactitol is oxidized by sorbitol dehydrogenase at only $\sim 3 \%$ of the rate for sorbitol (53). That ${ }^{125} \mathrm{I}$-albumin permeation was no greater in granulation tissue of galactose-fed rats than in diabetic rats, despite the very large difference in tissue polyol levels, is consistent with the hypothesis that metabolic imbalances (i.e., in the redox state of pyridine nucleotides and glutathione) resulting from increased flux of glucose through the polyol pathway, rather than absolute tissue polyol levels, mediate the functional and structural perturbations associated with increased polyol metabolism in various tissues. Other evidence in support of this hypothesis is the finding of Greene et al. that myo-inositol supplementation of the diet of diabetic rats normalizes myoinositol levels, $\mathrm{Na} / \mathrm{K}$-ATPase activity, and motor nerve conduction velocity without affecting sorbitol levels (7). Several groups of investigators has postulated that imbalances in the redox state of pyridine nucleotides and glutathione may play an important role in cataract formation (54-56).

On the other hand, Kinoshita (57) has proposed that intracellular edema produced by osmotic effects of intracellular polyol accumulation plays a critical role in the development of biochemical and metabolic changes involved in the pathogenesis of cataract formation in diabetic rats and in rats fed galactoseenriched diets. It is of interest in this regard that no evidence of endothelial swelling or edema is discernable in electron micrographs of granulation tissue vessels of galactose-fed rats or diabetic rats (unpublished data).

The finding that myo-inositol levels in granulation tissue of galactose-fed rats did not differ significantly from those of controls (Table VI) differs from our observations in diabetic rats in which myo-inositol levels are (significantly) decreased by 17$25 \%(28,29)$ and from reports by other investigators in which myo-inositol levels are generally reduced by $20-40 \%$ in nerve and lens of diabetic $(7,12,13,15,58,59)$ and galactose-fed $(4$, $13,58,59)$ rats. This finding is of particular interest in view of evidence suggesting that reduced myo-inositol levels play a critical role in mediating diabetes- and galactose-induced nerve damage $(7,57)$. On the other hand, the role of decreased myoinositol levels in the pathogenesis of diabetes- and galactoseinduced cataracts appears to be less well understood.

Previous investigators have demonstrated aldose reductase activity in the aorta and have reported that polyol production in the intact aorta and the activity of the enzyme isolated from aorta, brain, and skeletal muscle are modulated in vitro by a number of hormones and metabolites $(19,20)$. There have been 
no reports, however, linking increased in vivo metabolism of hexoses by the polyol pathway to impaired functional integrity of the aorta, i.e., increased vascular permeability, under pathophysiological conditions. This new observation in galactose-fed rats is consistent with recent observations in diabetic rats mentioned earlier (43) and raises the possibility that acceleration of atherosclerotic vascular disease in human diabetics may reflect arterial injury (resulting in increased permeation of endothelium by atherogenic lipoproteins) mediated by increased metabolism of glucose via the polyol pathway.

The finding that collagen solubility was increased in new granulation tissue of galactose-fed rats sharply contrasts with the marked decrease observed in diabetic rats $(28,29,31)$. On the other hand, net collagen accumulation is not affected by galactose ingestion or by diabetes $(28,29,31)$. An explanation for the divergent effects of diabetes and galactose feeding on collagen solubility is not readily apparent from these experiments on galactose-fed rats. The demonstration of prostatic atrophy in rats fed 25 and $50 \%$ galactose diets and the marked decrease in plasma testosterone levels in rats fed $50 \%$ galactose diets indicates that galactose-fed rats are, like diabetic rats, hypogonadal (61-63). The finding that collagen solubility is increased in (intact hypogonadal) galactose-fed rats is consistent with the finding that castration of nondiabetic rats results in increased collagen solubility (28). On the other hand, the finding that collagen solubility is decreased in (intact hypogonadal) diabetic rats suggests that some additional factor peculiar to the diabetic milieu, possibility insulinopenia, counteracts the hypogonadal state in the diabetic rat and leads to increased lysyl oxidase-mediated collagen crosslinking (28).

In light of observations in diabetic and nondiabetic rats, we can virtually exclude the possibility that the decreased collagen solubility in these galactose-fed rats is linked to the small (albeit statistically significant) increase in hexoses bound in ketoamine linkage to granulation tissue proteins. In diabetic rats, nonenzymatic glycosylation of granulation tissue protein is increased by $50 \%$ (vs. $10 \%$ in the galactose-fed rats) while collagen solubility is decreased (28); castration of diabetic rats has no effect on nonenzymatic glycosylation but completely prevents the diabetes-induced decrease in collagen solubility (28).

In summary, these findings: (a) demonstrate that consumption of galactose-enriched diets causes increased ${ }^{125} \mathrm{I}$-albumin permeation of the aorta and of vessels in the eye, kidney, sciatic nerve, and new granulation tissue analagous to that observed in diabetic rats; $(b)$ provide further evidence that imbalances in polyol/inositol metabolism are associated with increased vascular permeability independent of changes in collagen crosslinking (which is increased in the diabetic and decreased in galactosefed rats); and (c) provide new evidence that consumption of galactose-enriched diets induces a hypogonadal state in male rats.

\section{Acknowledgments}

This work was supported by the Kilo Diabetes and Vascular Research Foundation and by grants from the National Institutes of Health (HL13694, AM-20579, and RR-00954).

\section{References}

1. Mitchell, H. S. 1935. Cataract in rats fed on galactose. Proc. Soc. Exp. Biol. Med. 32:971-972.
2. Kinoshita, J. H. 1965. Cataracts in galactosemia. Invest. Ophthalmol. 4:786-799.

3. Gabbay, K. H., and J. J. Snider. 1972. Nerve conduction defect in galactose-fed rats. Diabetes. 21:295-300.

4. Sharma, A. K., P. K. Thomas, and R. W. R. Baker. 1976. Peripheral nerve abnormalities related to galactose administration in rats. J. Neurol. Neurosurg. Psychiatry. 39:794-802.

5. Gabbay, K. H. 1973. The sorbitol pathway and the complications of diabetes. N. Engl. J. Med. 288:831-836.

6. Cogan, D. G., J. H. Kinoshita, P. F. Kador, G. Robison, M. B. Datiles, M. Cobo, and C. Kupfer. 1984. Aldose reductase and complications of diabetes. Ann. Intern. Med. 101:82-91.

7. Greene, D. A., S. Lattimer, J. Ulbrecht, and P. Carroll. 1985. Glucose-induced alterations in nerve metabolism: current perspective on the pathogenesis of diabetic neuropathy and future directions for research and therapy. Diabetes Care. 8:290-299.

8. Dvornik, D., N. Simard-Duquesne, M. Krami, K. Sestanj, K. H. Gabbay, J. H. Kinoshita, S. D. Varma, and L. O. Merola. 1973. Polyol accumulation in galactosemic and diabetic rats: control by an aldose reductase inhibitor. Science (Wash. DC). 182:1146-1148.

9. Peterson, M. J., R. Sarges, C. E. Aldinger, and D. P. MacDonald. 1979. CP-45,634: a novel aldose reductase inhibitor that inhibits polyol pathway activity in diabetic and galactosemic rats. Metab. Clin. Exp. 28(Suppl. 1):456-461.

10. Kikkawa, R., I. Hatanaka, H. Yasuda, N. Kobayashi, Y. Shigeta, H. Terashima, T. Morimura, and M. Tsobushima. 1983. Effect of a new aldose reductase inhibitor, (E)-3-carboxymethyl-5-[(2E)-methyl-3-phenylpropenylidene]rhodanine(ONO-2235) on peripheral nerve disorders in streptozotocin-diabetic rats. Diabetologia. 24:290-292.

11. Simard-Duquesne, N., E. Greselin, R. Gonzalez, D. Dvornik. 1978. Prevention of cataract development in severely galactosemic rats by the aldose reductase inhibitor, tolrestat (42048). Proc. Soc. Exp. Biol. Med. 178:599-605.

12. Stribling, D., D. J. Mirrlees, H. E. Harrison, and D. C. N. Earl. 1985. Properties of ICI 128,436, a novel aldose reductase inhibitor, and its effects on diabetic complications in the rat. Metab. Clin. Exp. 34: 336-344.

13. Yue, D. K., M. A. Hanwell, P. M. Stachell, and J. R. Turtle. 1982. The effect of aldose reductase inhibition on motor nerve conduction velocity in diabetic rats. Diabetes. 31:789-794.

14. Judzewitsch, R. G., J. B. Jaspan, K. S. Polonsky, C. R. Weinberg, J. B. Halter, E. Haler, M. A. Pfeifer, C. Vukadinovic, L. Bernstein, M. Schneider, K-Y Liang, K. H. Gabbay, A. H. Rubenstein, and D. Porte, Jr. 1983. Aldose reductase inhibition improves nerve conduction velocity in diabetic patients. $N$. Engl. J. Med. 308:119-125.

15. Tomlinson, D. R., R. J. Moriarty, and J. H. Mayer. 1984. Prevention and reversal of defective axonal transport and motor nerve conduction velocity in rats with experimental diabetes by treatment with the aldose reductase inhibitor sorbinil. Diabetes. 33:470-476.

16. Akagi, Y., P. F. Kador, T. Kuwabara, and J. H. Kinoshita. 1983. Aldose reductase in human retinal mural cells. Invest. Ophthalmol. \& Visual Sci. 24:1516-1519.

17. Kennedy, A., R. N. Frank, and S. D. Varma. 1983. Aldose reductase activity in retinal and cerebral microvessels and cultured vascular cells. Invest. Ophthalmol. \& Visual Sci. 24:1250-1253.

18. Kern, T. S., and R. L. Engerman. 1985. Hexitol production by canine retinal microvessels. Invest. Ophthalmol. \& Visual Sci. 26:382384.

19. Clements, R. S., Jr., A. D. Morrison, and A. I. Winegrad. 1969. Polyol pathway in aorta: regulation by hormones. Science (Wash. DC). 166:1007-1008.

20. Das, B., and S. K. Srivastava. 1985. Activation of aldose reductase from human tissues. Diabetes. 34:1145-1151.

21. Ludvigson, M. A., and R. L. Sorenson. 1980. Immunohistochemical localization of aldose reductase. II. Rat eye and kidney. Diabetes. 29:450-459.

22. Beyer-Mears, A., L. Ku, and M. P. Cohen. 1984. Glomerular 
polyol accumulation in diabetes and its prevention by oral sorbinil. $\mathrm{Di}$ abetes. 33:604-607.

23. Frank, R. N., R. J. Keirn, A. Kennedy, and K. W. Frank. 1983. Galactose-induced retinal capillary basement membrane thickening: prevention by sorbinil. Invest. Ophthalmol. \& Visual Sci. 24:1519-1524.

24. Robison, W. G., Jr., P. F. Kador, and J. H. Kinoshita. 1983. Retinal capillaries: basement membrane thickening by galactosemia prevented with aldose reductase inhibitor. Science (Wash. DC). 221: $1177-1179$.

25. Robison, Jr., W. G., P. F. Kador, Y. Akagi, J. H. Kinoshita, R. Gonzalez, and D. Dvornik. 1986. Prevention of basement membrane thickening in retinal capillaries by a novel inhibitor of aldose reductase, tolrestat. Diabetes. 35:295-299.

26. Engerman, R. L., and J. W. Kramer. 1982. Dogs with induced or spontaneous diabetes as models for the study of human diabetes mellitus. Diabetes. 31(Suppl. 1):26-29.

27. Kilzer, P., K. Chang, J. Marvel, E. Rowold, P. Jaudes, S. Ullensvang, C. Kilo, and J. R. Williamson. 1985. Albumin permeation of new vessels is increased in diabetic rats. Diabetes. 34:333-336.

28. Williamson, J. R., E. Rowold, K. Chang, J. Marvel, M. Tomlinson, W. R. Sherman, K. E. Ackermann, R. A. Berger, and C. Kilo. 1986. Sex steroid-dependency of diabetes-induced changes in polyol metabolism, vascular permeability and collagen crosslinking. Diabetes. 35:20-27.

29. Williamson, J. R., K. Chang, E. Rowold, J. Marvel, M. Tomlinson, W. R. Sherman, K. E. Ackermann, and C. Kilo. 1985. Sorbinil prevents diabetes-induced increases in vascular permeability but does not alter collagen crosslinking. Diabetes. 34:703-705.

30. Williamson, J. R., K. Chang, E. Rowold, J. Marvel, M. Tomlinson, W. R. Sherman, K. E. Ackermann, and C. Kilo. 1986. Diabetes-induced increases in vascular permeability and changes in granulation tissue levels of sorbitol, myo-inositol, chiro-inositol, and scyllo-inositol are prevented by sorbinil. Metab. Clin. Exp. 35:41-45.

31. Chang, K., J. Uitto, E. A. Rowold, G. A. Grant, C. Kilo, and J. R. Williamson. 1980. Increased collagen crosslinkages in experimental diabetes: reversal by B-aminopropionitrile (BAPN) and D-penicillamine. Diabetes. 29:778-781.

32. Kilzer, P., K. Chang, J. Marvel, C. Kilo, and J. R. Williamson. 1985. Tissue differences in vascular permeability changes induced by histamine. Microvasc. Res. 30:270-285.

33. Miller, E. J., and R. K. Rhodes. 1982. Preparation and characterization of the different types of collagen. Methods Enzymol. 82:3364.

34. Flukiger, R., and K. H. Winterhalter. 1976. In vitro synthesis of hemoglobin $A_{1 c}$. FEBS (Fed. Eur. Biochem. Soc.) Lett. 71:356.

35. Kivirikko, K. I., O. Laitinen, and D. J. Prockop. 1967. Modifications for a specific assay of hydroxyproline in urine. Anal. Biochem. 19:249-255.

36. Moore, S., and W. H. Stein. 1954. A modified ninhydrin reagent for the photometric determination of amino acids and related compounds. J. Biol. Chem. 211:907-913.

37. Berg, R. A. 1982. Determination of 3- and 4-hydroxyproline. Methods Enzymol. 82:372-398.

38. Dyck, P. J., W. R. Sherman, L. M. Hallcher, F. J. Service, P. C. O'Brien, L. A. Grina, P. J. Palumbo, and C. J. Swanson. 1980. Human diabetic endoneurial sorbitol, fructose, and myo-inositol related to sural nerve morphometry. Ann. Neurol. 8:590-596.

39. Huggett, A., and D. A. Mixon. 1957. Use of glucose oxidase, peroxidase and O-dianisidine in determination of blood and urinary glucose. Lancet. ii:368-379.

40. DeVerdier, C. H., and M. Hjelm. 1962. A galactose-oxidase method for the determination of galactose in blood plasma. Clin. Chim. Acta. 7:742-744.
41. Cicero, T. J., E. R. Meyer, W. G. Wiest, J. W. Olney, and R. B. Bell. 1975. Effects of chronic morphine administration on the reproductive system of the male rat. J. Pharmacol. Exp. Ther. 192:542-548.

42. Chang, K., C. Weigel, J. R. Jeffrey, R. G. Tilton, and C. Kilo. 1986. Diabetes-induced increased albumin permeation in the eye: prevention by inhibitors of aldose reductase. Diabetes. 35(Suppl. 1):101A. (Abstr.)

43. Tilton, R. G., L. LaRose, and C. Prater. 1986. Additive effects of hypertension- and diabetes-induced increased albumin permeation in eyes, aorta, and kidney of rats. Diabetes. 35(Suppl. 1):41A. (Abstr.)

44. Sterling, R. E. and P. L. Day. 1951. Blood sugar levels and cataract in alloxan-treated, galactose-fed and xylose-fed weanling rats. Proc. Soc. Exp. Biol. 78:431-433.

45. Seneviratne, K. N. 1972. Permeability of blood nerve barriers in the diabetic rat. J. Neurol. Neurosurg. Psychiatry. 35:156-162.

46. Ohi, T., J. F. Poduslo, P. J. Dyck. 1985. Increased endoneurial albumin in diabetic polyneuropathy. Neurology. 35:1790-1791.

47. Malmgren, L. T., J. Jakobsen, and Y. Olsson. 1979. Permeability of blood-nerve barrier in galactose-fed rats. Exp. Neurol. 66:758-770.

48. Jakobsen, J., L. Malmgren, and Y. Olsson. 1978. Permeability in the blood-nerve barrier in the streptozotocin-diabetic rat. Exp. Neurol. 60:277-285.

49. Mitchell, H. S. 1936. Susceptibility of different strains of rats to nutritional cataract. J. Nutr. 12:447.

50. Norton, E. W. D., and F. Gutman. 1967. Diabetic retinopathy studied by fluorescein angiography. Ophthalmologica. 150:5-17.

51. Kohner, E. M., C. T. Dollery, J. W. Paterson, and N. W. Oakley. 1967. Arterial fluorescein studies in diabetic retinopathy. Diabetes. 16: 1-10.

52. Hayman, S., and J. H. Kinoshita. 1965. Isolation and properties of lens aldose reductase. J. Biol. Chem. 240:877-882.

53. Smith, M. G. 1962. Polyol dehydrogenases. Crystallization of the L-Iditol dehydrogenase of sheep liver. Biochem. J. 83:135-144.

54. Crabbe, M. J. C., S. Wolff, A. B. Halder, and H-H. Ting. 1981. Diabetic cataracts - is aldose reductase important? Metab. Pediatr. Ophthalmol. 5:33-38.

55. Gonzalez, A-M., M. Sochor, and P. McLean. 1983. The effect of an aldose reductase inhibitor (sorbinil) on the level of metabolites in lenses of diabetic rats. Diabetes. 32:482-485.

56. Gonzalez, R. G., P. Barnett, J. Aguayo, H-M. Cheng, and L. T. Chylack, Jr. 1984. Direct measurement of polyol pathway activity in the ocular lens. Diabetes. 33:196-199.

57. Kinoshita, J. H. 1984. Concept of aldose reductase and diabetic cataracts. Ann. Intern. Med. 101:82-91.

58. Stewart, M. A., W. R. Sherman, M. M. Kurien, G. I. Moonsammy, and $M$. Wisgerhof. 1967. Polyol accumulations in nervous tissue of rats with experimental diabetes and galactosemia. J. Neurochem. 14:10571066.

59. Broekhuyse, R. M. 1968. Changes in myo-inositol permeability in the lens due to cataractous conditions. Biochim. Biophys. Acta. 163: 269-272.

60. Winegrad, A. I., D. A. Simmons, and D. B. Martin. 1983. Has one diabetic complication been explained? N. Engl. J. Med. 308:152154.

61. Paz, G., Z. T. Homonnai, and N. Drasnin. 1978. Fertility of the streptozotocin-diabetic male rat. Andrologia. 10:127-136.

62. Howland, B. E., and E. J. Zebrowski. 1976. Some effects of experimentally-induced diabetes on pituitary-testicular relationships in rats. Horm. Metab. Res. 8:465-469.

63. Saksena, S. K., and I. F. Lau. 1979. Variations in serum androgens, estrogens, progestins, gonadotropins, and prolactin levels in male rats from prepubertal to advanced age. Exp. Aging Res. 5:179-194. 